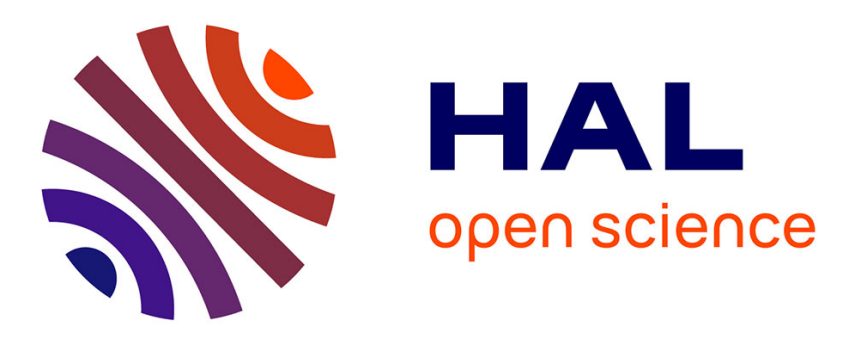

\title{
Drift effects and trap analysis of power-GaN-HEMT under switching power cycling
}

Manuel A González-Sentís, Patrick Tounsi, Alain Bensoussan, Arnaud Dufour

\section{To cite this version:}

Manuel A González-Sentís, Patrick Tounsi, Alain Bensoussan, Arnaud Dufour. Drift effects and trap analysis of power-GaN-HEMT under switching power cycling. Science of Electronics, Technologies of Information and Telecommunication, SETIT'18, Dec 2018, Hammamet, Tunisia. hal-02131990

\section{HAL Id: hal-02131990 \\ https://hal.laas.fr/hal-02131990}

Submitted on 16 May 2019

HAL is a multi-disciplinary open access archive for the deposit and dissemination of scientific research documents, whether they are published or not. The documents may come from teaching and research institutions in France or abroad, or from public or private research centers.
L'archive ouverte pluridisciplinaire HAL, est destinée au dépôt et à la diffusion de documents scientifiques de niveau recherche, publiés ou non, émanant des établissements d'enseignement et de recherche français ou étrangers, des laboratoires publics ou privés. 


\title{
Drift effects and trap analysis of power-GaN-HEMT under switching power cycling
}

\author{
Manuel A González-Sentís ${ }^{1,2,3}$, Patrick Tounsi ${ }^{2}$, Alain Bensoussan ${ }^{3}$, Arnaud Dufour ${ }^{1}$ \\ ${ }^{1}$ CNES, Toulouse 31400, France \\ ${ }^{2}$ LAAS-CNRS, Toulouse 31400, France \\ ${ }^{3}$ IRT Saint-Exupéry, Toulouse 31423, France \\ mgonzaleelaas.fr
}

\begin{abstract}
This paper studies the impact of the aging on power GaN transistors in switching conditions. The devices under test are commercial discrete enhancement mode gallium-nitride HEMT. We present a power cycling test platform that controls the switching conditions such as frequency, duty cycle, and gate voltage; as well as drain current and drain voltage. We have measured specific parameters before and after the power cycling in order to detect indicators for each drift effect. We measure not only the electrical parameters given by datasheet, but also the traps causing Dynamic On-State Resistance, an specific drift effect of this technology which compromises high frequency efficiency in switching power converters.
\end{abstract}

Keywords: Power electronics, GaN HEMT, reliability, energy management, wide bandgap semiconductors.

\section{Introduction}

In the last few years, gallium nitride $(\mathrm{GaN})$ has become an excellent material for the fabrication of power transistors. Normally-off High-Electron Mobility Transistors (HEMTs) in $\mathrm{AlGaN} / \mathrm{GaN}$ heterojunction are the most promising devices for space and automotive applications. This transistor offer offers very interesting performances for power switching converters such as high power densities and fast switching -resulting in smaller, lighter power converters- and low on-resistance. In addition, like other wide-bandgap materials, $\mathrm{GaN}$ is inherently radiation-hard material and tolerates higher operational temperatures.

Nevertheless, large-scale deployment of GaN HEMT remains limited because of insufficient technological maturity, high cost manufacturing and reliability. The comprehension of the GaN devices specific failure mechanisms is unavoidable to use those devices in harsh environment under specific mission conditions.

As shown in [1], established test procedures from silicon are not sufficient to cover the reliability requirements for $\mathrm{GaN}$, especially regarding charge trapping and Dynamic On-Resistance. Other authors [2] suggest new degradation indicators to track the evolution of power GaN HEMTS. Anyway, all of these studies agree that further studies 
and new methods are necessary to better understand and measure the degradation mechanisms of power GaN HEMT.

In order to obtain reliability data of power GaN devices, we apply a power-cycling test on discrete commercial devices. We choose the stress conditions to activate specific drift effects. The power-cycling test is described on section 2, the measurements are explained on section 3 , and the results are shown on section 4 .

\section{Power-cycling test}

\subsection{Description and purpose}

The aging of GaN devices depend on the kind of stress applied. That is the reason why the aim of this power-cycling test is to control all the electrical parameters. In power switching converters, the stress changes on each phase of the switching cycle [3]:

- During off-state phase, the device is under high internal electric field. The losses on this phase are proportional to drain leakage current and drain voltage. A dynamic increase of on-resistance can be observed due to charge trapping effects (see fig.3) under high electric field in off-state [4].

- In the on-state phase, losses are generated by high drain current and on-resistance. If on-resistance is increased dynamically by trapping effects, on-state losses can be significant.

- During the switching phase, losses depend on the hard or soft switching operation and the duration of the switching event. The switching losses can dominate the overall losses on hard switching mode.

\subsection{Power-cycling set-up}

We test discrete $200 \mathrm{~V}$ GaN power devices with $\mathrm{R}_{\mathrm{DSON}}=50 \mathrm{~m} \Omega, \mathrm{I}_{\mathrm{DMAX}}=8.5 \mathrm{~A}$ and $\mathrm{V}_{\mathrm{GS}(\mathrm{TH}) \mathrm{MAX}}=2.5 \mathrm{~V}[5]$. The devices are tested without packaging or heat sink; they are soldered on the DUT PCB (see Fig.1). We plug the DUT PCB to the power board with a connector. After the stress, the DUT PCB is connected to the measure instruments.

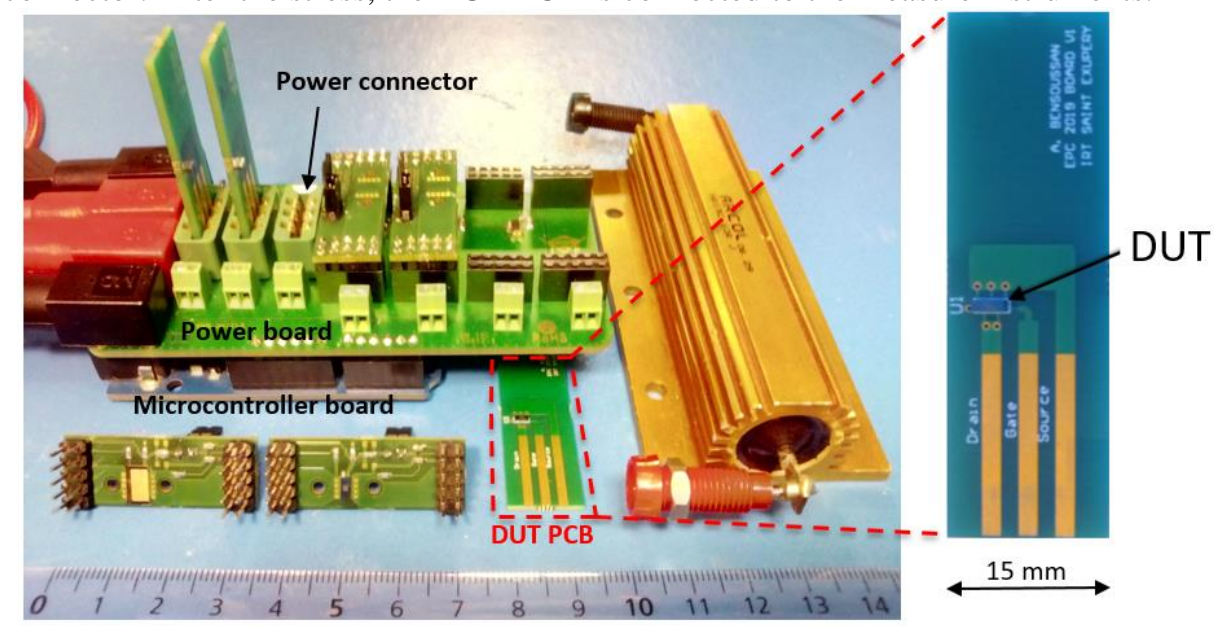

Fig. 1. Power cycling set-up and DUT PCB 
We apply power-cycling tests to obtain reliability data in a short period of time. Two main sources of stress are regulated: the gate control and the power parameters.

- The gate control consists of a microcontroller board with different PWM channels independently programmable. In order to protect the gate of the PWM overshoots, we use a gate driver compatible with GaN HEMT (LM5114), with pull-up and pulldown resistors as recommended by manufacturers [6]. We can control the frequency, the duty cycle and the gate voltage for each device under test.

- The power stress parameters controlled are the drain voltage $\mathrm{V}_{\mathrm{DS}}$ and the drain current $\mathrm{I}_{\mathrm{DS}}$, which is fixed by the power resistors.

\begin{tabular}{|l|l|l|l|}
\hline & Stress 1 & Stress 2 & Stress 3 \\
\hline Drain current & $1 \mathrm{~A}$ & $2 \mathrm{~A}$ & $4 \mathrm{~A}$ \\
\hline Drain voltage & $10 \mathrm{~V}$ & $20 \mathrm{~V}$ & $20 \mathrm{~V}$ \\
\hline Duty cycle & 0.5 & 0.25 & 0.1 \\
\hline Duration & $30 \mathrm{~h}$ & $30 \mathrm{~h}$ & $30 \mathrm{~h}$ \\
\hline
\end{tabular}

Table 1. Power-cycling stress parameters

To fix the stress conditions we use a step stress: incremental levels of drain current in order to find the stress parameters that cause failure modes. We summarize the stress parameters in table 1. In order the study the influence of the gate voltage, we realize two power-cycling tests side by side: one with $\mathrm{V}_{\mathrm{G}}=4 \mathrm{~V}$ and other with $\mathrm{V}_{\mathrm{G}}=5 \mathrm{~V}$.

When fixing the stress parameter, we have taken into account the temperature. In [7] the authors show that high temperature swings $\left(\Delta \mathrm{T}=100^{\circ} \mathrm{C}\right)$ can generate mechanical degradation, due to the high power densities in power GaN HEMTs. We want to study internal degradation mechanisms, not solder or packaging issues. In order to be sure that we do not activate thermo-mechanical failure mechanisms, such as delamination of solder due to high temperature swings, we measure the temperature with an infrared (IR) camera (see fig.2). We make sur that the chosen stress parameters do no heat the device under test at more than $100^{\circ} \mathrm{C}$ and $\Delta \mathrm{T}<25^{\circ} \mathrm{C}$. The switching frequency, an important parameter that determines $\Delta \mathrm{T}$, is fixed to $1 \mathrm{kHz}$ after the IR camera tests.

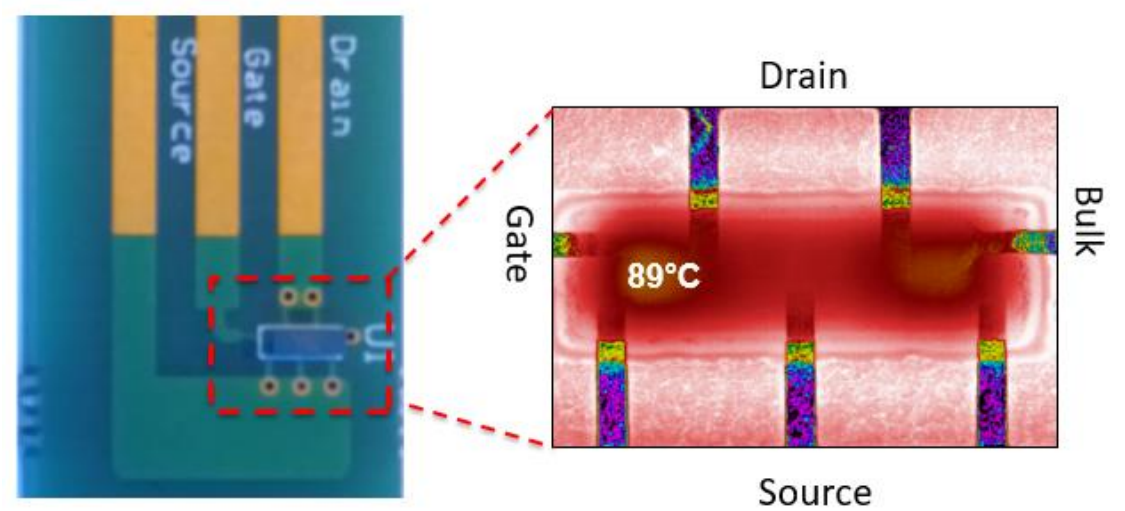

Fig. 2. DUT PCB and IR image of the device 


\section{$3 \quad$ Measurements}

The characterization consists of extracting the $I_{D}\left(V_{D S}\right)$ curve, the $I_{D}\left(V_{G S}\right)$ curve -from which we deduce the threshold voltage $\mathrm{V}_{\mathrm{TH}^{-}}$and leakage current. Comparing the different stress and characterizations throughout the power cycling, we can identify specific degradation phenomenon shown in table 2.

\begin{tabular}{|c|c|c|}
\hline DRIFT EFFECT & PHYSICAL ORIGIN & MEASUREMENT \\
\hline $\begin{array}{c}\text { Dynamic RDSON } \\
\text { increase }\end{array}$ & $\begin{array}{c}\text { Trapping in GaN buffer and surface } \\
\text { trapping between drain and gate }\end{array}$ & $\mathrm{C}_{\mathrm{G}}\left(\mathrm{V}_{\mathrm{G}}\right)$ hysteresis measurement \\
\hline $\begin{array}{c}\text { Time-Depend- } \\
\text { ent degradation }\end{array}$ & $\begin{array}{c}\text { Generation of drain-source, gate- } \\
\text { channel paths and vertical breakdown }\end{array}$ & Leakage current measurement \\
\hline $\mathrm{V}_{\mathrm{TH}}$ shift & Electron trapping beneath the gate & $\begin{array}{c}\mathrm{I}_{\mathrm{D}}\left(\mathrm{V}_{\mathrm{GS}}\right) \text { characterisation } \\
\mathrm{I}_{\mathrm{D}}\left(\mathrm{V}_{\mathrm{DS}}\right) \text { for several } \mathrm{V}_{\mathrm{GS}} \text { values }\end{array}$ \\
\hline $\begin{array}{c}\mathrm{I}_{\mathrm{G}} \text { leakage } \\
\text { current }\end{array}$ & $\begin{array}{c}\text { Path creation in the gate region, } \\
\text { Trap-assisted tunnelling }\end{array}$ & $\begin{array}{c}\mathrm{C}_{\mathrm{G}}\left(\mathrm{V}_{\mathrm{G}}\right) \text { hysteresis measurement } \\
\mathrm{I}_{\mathrm{G}}\left(\mathrm{V}_{\mathrm{GS}}\right) \text { measurement }\end{array}$ \\
\hline
\end{tabular}

Table 2. Drift effects in GaN HEMTs, physical origin and measurement to test each effect, based in [8].

The measuring instrument for I(V) curves and leakage currents is the HP4142B. To extract the $\mathrm{C}(\mathrm{V})$ curves we use the Agilent B1505. For the extraction of $\mathrm{V}_{\mathrm{TH}}$ we use the linear extrapolation method in the linear region in the $\mathrm{I}_{\mathrm{D}}\left(\mathrm{V}_{\mathrm{GS}}\right)$ curve, as shown in [9].

\subsection{Trapping effects measurement}

\section{Dynamic On-Resistance}

One of the purposes of this work is to study the Dynamic $\mathrm{R}_{\mathrm{DSON}}$ evolution during the power cycling. Dynamic On-Resistance, also called "current collapse" for RF GaN HEMT [10], generates additional losses in on-state and compromises high frequency efficiency. Dynamic $R_{D S O N}$ is a transient phenomenon generated by trapped electrons (see fig.3). The On-Resistance just after the turn-on is higher than the $\mathrm{R}_{\mathrm{DSON}}$ value given by the datasheet. The trapped charge creates a local electric field that degrade the conductivity in the channel [10]. Trapped electrons must be released to achieve the nominal $\mathrm{R}_{\mathrm{DSON}}$.

On the devices under test, this transient effect is on the order of microseconds depending on the stress applied. Dynamic $R_{D S O N}$ transient is faster in high temperatures because trapping and detrapping time-constants decrease with temperature [10]. The $\max \mathrm{R}_{\mathrm{DSON}}$ depends on avaiable traps, i.e. impurities in the $\mathrm{AlGaN}$ layer or $\mathrm{SiN}$ passivation, and dislocations and defects in the $\mathrm{GaN}$ buffer. A high $\mathrm{V}_{\mathrm{DS}}$ during off-state and a long the time in off-state increase the $\mathrm{R}_{\mathrm{DSON}}$ after the turn-on. This is because electrons have more energy (higher electric field) and more time to be trapped. When the time in off-state is long enough to fill all the traps, the $\mathrm{R}_{\mathrm{DSON}}$ will not increase anymore. 


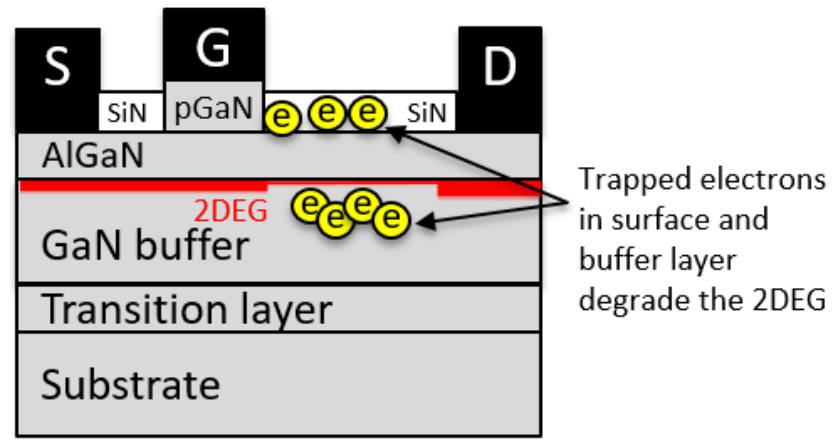

Fig. 3. Trapped electrons just after turn-on in a power GaN HEMT.

\section{Traps measurement method}

In order to investigate the evolution of traps during the aging of the transistors, we have realized $\mathrm{C}_{\mathrm{G}}(\mathrm{V})$ curves on the gate under sweeps from $-4 \mathrm{~V}$ to $6 \mathrm{~V}$ and down from $6 \mathrm{~V}$ to $-4 \mathrm{~V}$. The arrow nearby each curve marks sweep directions (see fig.2). We can observe a hysteresis in the capacitance expressed by a shift during the return sweep.

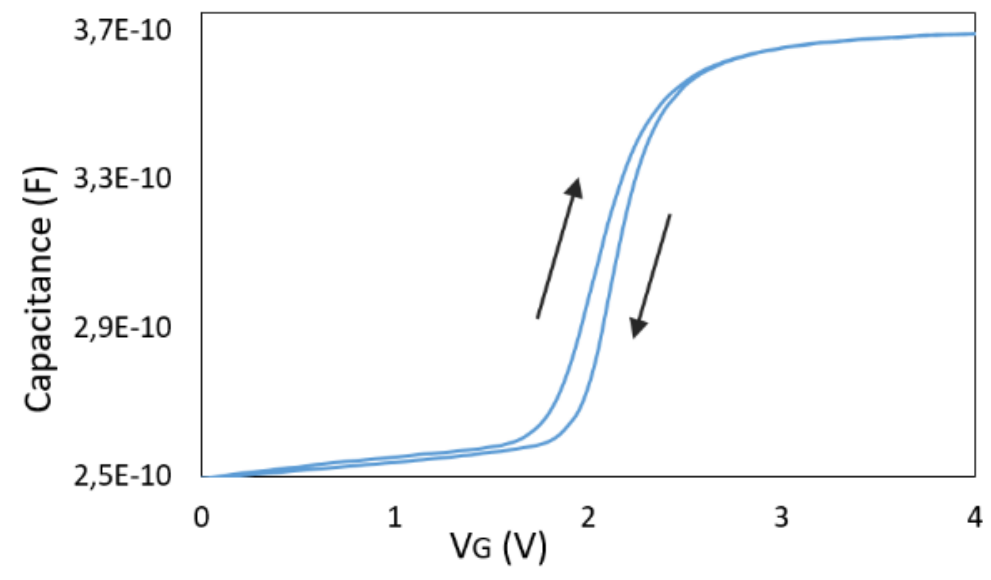

Fig. 4. $\mathrm{C}_{\mathrm{G}}(\mathrm{V})$ characteristic of the GaN HEMT before the power cycling test.

We realize the $\mathrm{C}_{\mathrm{G}}(\mathrm{V})$ measurement at $1 \mathrm{MHz}$, at $300 \mathrm{~K}$ and with a step of $50 \mathrm{mV}$. The surface enclosed in the curve can be explained as injection and trapping off electrons [11]. Note that the surface enclosed is an electrical charge: capacitance $(F)$ multiplied by a voltage $(\mathrm{V})$. 


\section{$4 \quad$ Results and discussion}

Figure 5 summarizes measured gate leakage current $\mathrm{I}_{\mathrm{G}}$ of eight DUTs during the power cycling test. For the DUTs 2 to 5 (driven at $\mathrm{V}_{\mathrm{G}}=5 \mathrm{~V}$ ), it is observed that IG rises above the max given by the datasheet after the stress S1. However, they still work after $\mathrm{S} 1$. Nevertheless, DUT4 and DUT5 failed after S3, with $\mathrm{I}_{\mathrm{G}}>100 \mathrm{~mA}$ (the saturation of the measuring instrument).

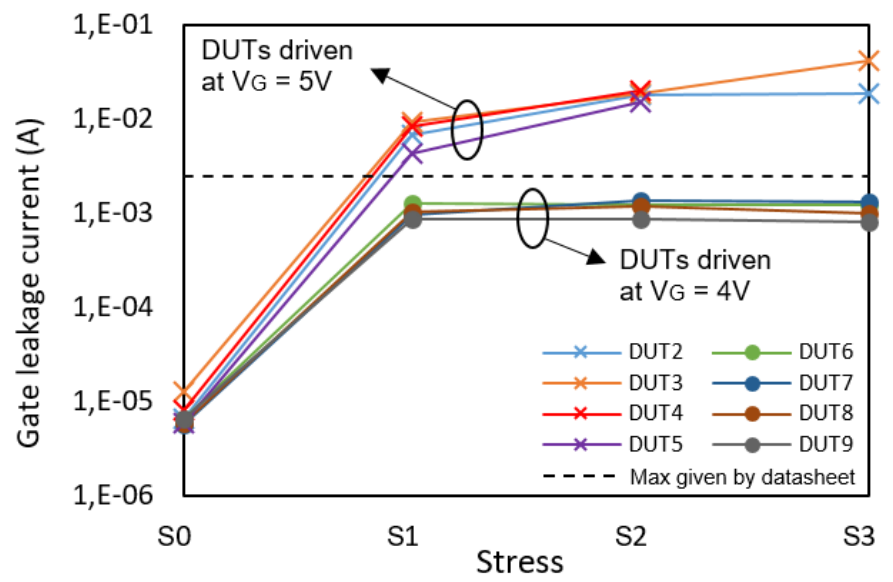

Fig. 5. Measured gate leakage current during the power cycling test. Note that DUTs 2 to 5 are driven at $\mathrm{VG}_{\mathrm{G}}=5 \mathrm{~V}$ and DUTs 6 to 8 are driven at $\mathrm{VG}_{\mathrm{G}}=4 \mathrm{~V}$.

In contrast, the DUTs driven at $\mathrm{V}_{\mathrm{G}}=4 \mathrm{~V}$ present a gate leakage current below the max given by datasheet. We observed that there is an initial degradation after $\mathrm{S} 1$, and then the gate leakage current remains stable during the rest of the power cycling.

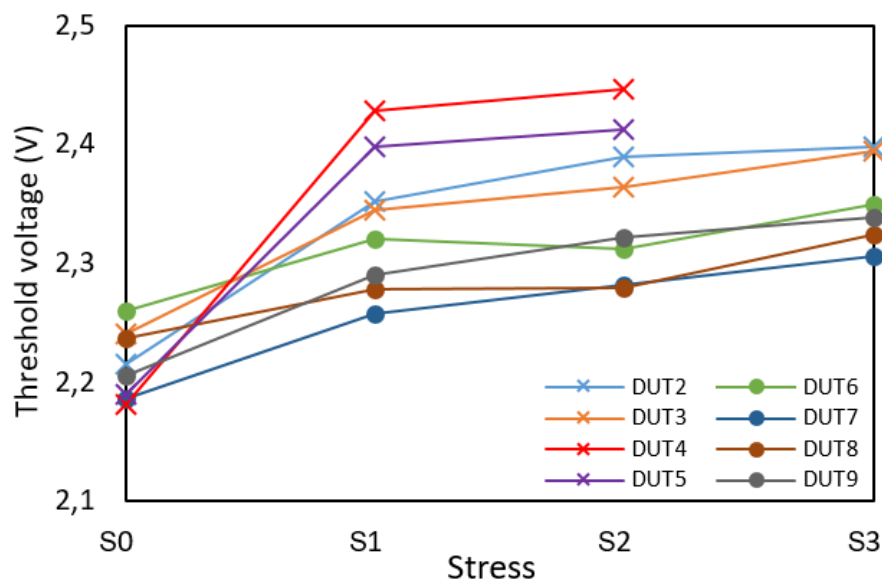

Fig. 6. Measured gate threshold voltage during the power cycling. The curve shows that the $\mathrm{V}_{T H}$ shift after the power cycling is more significant in DUTs driven at $\mathrm{V}_{\mathrm{G}}=5 \mathrm{~V}$. 
Figures 7 and 8 shows the evolution of the $\mathrm{C}_{\mathrm{G}}(\mathrm{V})$ curve of a DUT driven at $\mathrm{V}_{\mathrm{G}}=5 \mathrm{~V}$ and $\mathrm{V}_{\mathrm{G}}=4 \mathrm{~V}$ during the power cycling.

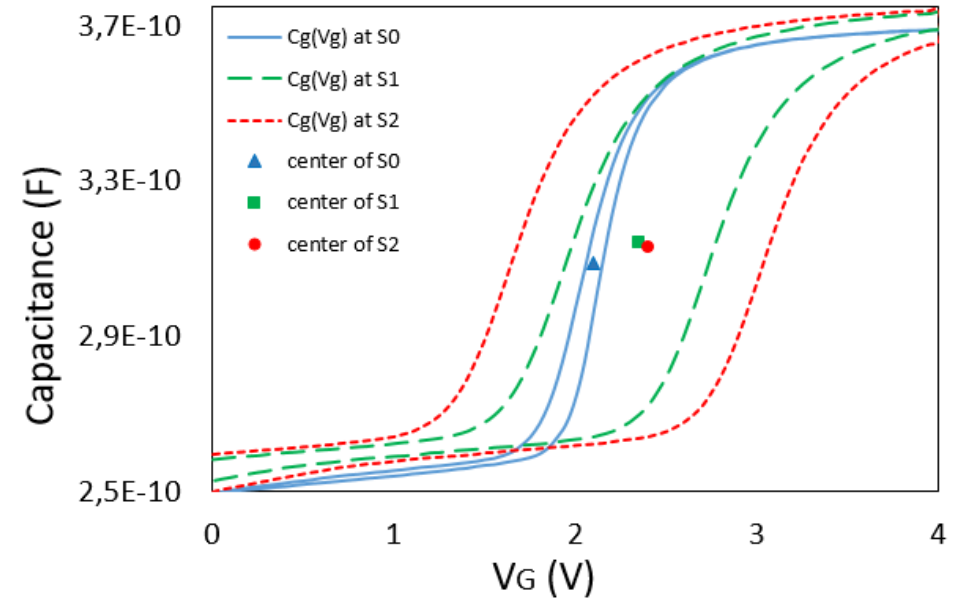

Fig. 7. $\mathrm{C}_{\mathrm{G}}(\mathrm{V})$ characteristic a $\mathrm{GaN}$ HEMT driven at $\mathrm{V}_{\mathrm{G}}=5 \mathrm{~V}$. In blue, before the power cycling, in green after stress $\mathrm{S} 1$ and in red after $\mathrm{S} 2$.

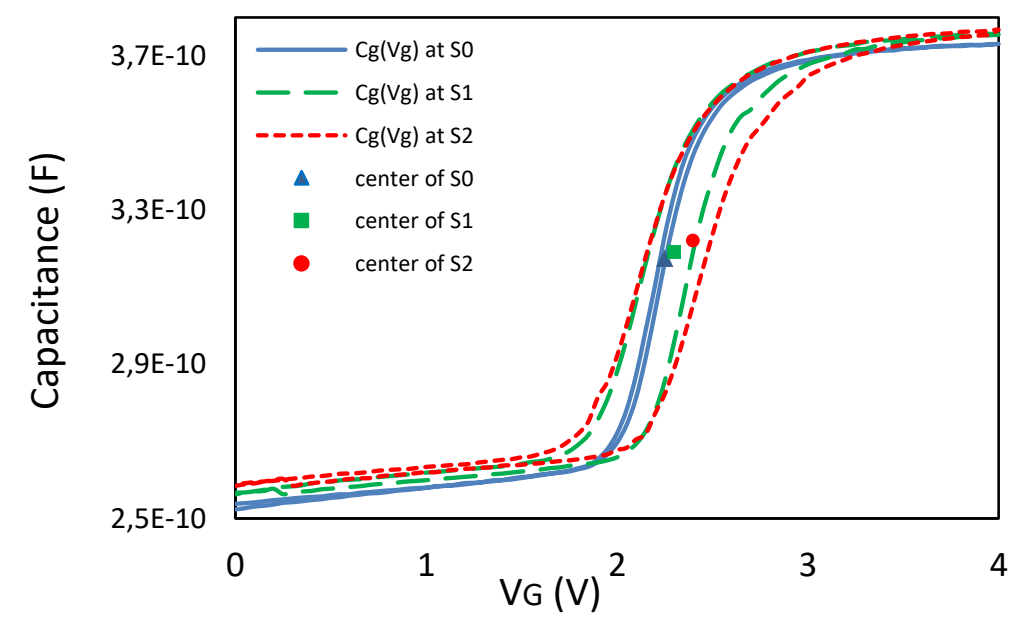

Fig. 7. $\mathrm{C}_{\mathrm{G}}(\mathrm{V})$ characteristic a GaN HEMT driven at $\mathrm{V}_{\mathrm{G}}=4 \mathrm{~V}$

We can observe that the hysteresis surface increases in devices driven at $\mathrm{V}_{\mathrm{G}}=5 \mathrm{~V}$ more than in devices driven at $\mathrm{V}_{\mathrm{G}}=4 \mathrm{~V}$. By observing the center of each surface, note that the shift of the $\mathrm{C}_{\mathrm{G}}(\mathrm{V})$ characteristic is similar that the shift on the threshold voltage shown in figure 6 . 


\section{Conclusion and future work}

We have introduced a power cycling test environment for a discrete GaN power transistors tacking into account the specific failure mechanisms in power GaN HEMT and thermo-mechanical issues. Failure progresses are observed with measuring diverse electrical parameters. We suggested $\mathrm{C}_{\mathrm{G}}(\mathrm{V})$ curves to investigate the evolution of traps during the test, and the $\mathrm{C}_{\mathrm{G}}(\mathrm{V})$ surface hysteresis as an interesting degradation indicator to track the evolution of trapping effects. We propose that the new traps created during the power cycling may be originated by overshoots on the gate voltage during the power cycling on DUTs driven at $\mathrm{V}_{\mathrm{G}}=5 \mathrm{~V}$.

Therefore, future research should be directed in order to approve or deny certain hypotheses and to clarify the origin of the traps by realizing C-DLTS measurements, and $\mathrm{R}_{\mathrm{DSON}}$ measurements to make a link between $\mathrm{C}_{\mathrm{G}}(\mathrm{V})$ hysteresis and Dynamic On-Resistance degradation.

\section{Acknowledgments}

This work is conducted in the frame of the IRT Saint-Exupery Robustness Electronic project sponsored by Airbus Operations, Airbus Group Innovations, Continental Automotive France, Hirex Engineering, Nexio, Safran Electrical \& Power, Thales Alenia Space France, Thales Avionics and the French National Agency for Research (ANR).

\section{References}

1. Josef Lutz and Jörg Franke. "Reliability and reliability investigation of wide-bandgap power devices" invited paper ESREF 2018.

2. J.Z. Fu, F. Fouquet, et al. "Evolution of C-V and I-V characteristics for a commercial 600V GaN GIT power device under repetitive short-circuit tests" ESREF 2018

3. Matteo Meneghini et al. "Power GaN Devices" Springer, 2017 pp. 299-300.

4. Ke Li et al. "GaN-HEMT RDSON characterisation and modelling" COMPEL IEEE, 2016.

5. EPC Corporation, "EPC2019 Enhancement Mode Power Transistor," datasheet, Sep. 2015

6. Alex Lidow et al. "eGaN FET Drivers and Layout Considerations" EPC Corporation, 2016

7. S. Song et al. "Failure Mechanism Analysis of a Discrete 650V Enhancement Mode GaNon-Si Power Device with Reverse Conduction Accelerated Power Cycling Test, IEE 2017

8. Matteo Meneghini et al. "Reliability and failure analysis in power GaNHEMTs: an overview" IEEE, June 2017.

9. L. Dobresc, M. Petrov et al. "Threshold Voltage Extraction Methods for MOS Transistors" CAS 2000 Proceedings IEEE, Oct 2000.

10. Matteo Meneghini et al. "Buffer Traps in Fe-Doped AlGaN/GaN HEMTs" IEEE Dec. 2014

11. S. Saadaoui, M.M. Ben Salem, M. Gassoumi, H. Maaref, C. Gaquière, J. Appl. Phys., 110 (2011), p. 013701 